\title{
Effects of hydrostatic pressure on mouse sperm
}

\author{
Karimi $\mathrm{N}^{1}$, Bahrami Kamangar $\mathrm{P}^{1}$, Azadbakht $\mathrm{M}^{1}$, Amini $\mathrm{A}^{1}$, Amiri $\mathrm{I}^{2}$ \\ Department of Biology, Faculty of Basic Sciences, Razi University, Kermanshah, Iran. \\ azadbakhtm_tmu@yahoo.com
}

\begin{abstract}
Objectives: The objective of this study was to investigate the abnormalities in sperm after exposure to hydrostatic pressure.

Background: Hydrostatic pressure acting on the cells is one of the fundamental environmental mechanical forces. Disorders of relationship between the cells and this mechanical force, such as when pressure varies beyond physiological limits, can lead to disease or pathological states. Sperm exposed to different range of hydrostatic pressure within male reproductive system and after entering the female reproductive system.

Methods: Sexually mature male NMRI mice, 8-12 weeks-old were sperm donors. Sperms were separated from the caudal epididymis and maintained in Ham's F-10 culture medium supplemented with $10 \%$ FBS and divided into control and treatments. Sperm suspensions in the treatments were placed within pressure chamber and were subjected to increased hydrostatic pressure of 25,50 and $100 \mathrm{mmHg}$ (treatment I, II and III) above atmospheric pressure for 2 and $4 \mathrm{~h}$. Sperm viability, motility, morphology, DNA integrity and fertilizing ability were assessed and compared with control.

Results: Results showed that hydrostatic pressure dependent on ranges and time manner reduced sperm quality due to adverse effect on viability, motility, morphology, DNA integrity and fertilizing ability in all of treatments, especially after $4 \mathrm{~h}(\mathrm{p}<0.05)$.

Conclusion: Our data revealed hydrostatic pressure reduces sperm quality as a consequence of adverse effects on sperm parameters and may cause male infertility or subfertility (Tab. 5, Ref. 5). Text in PDF www.elis.sk.

Key words: hydrostatic pressure, sperm, mouse.
\end{abstract}

Numerous studies about causes of infertility or subfertility of men have been reported. Environmental causes including: physical-mechanical, chemical and sperm parameters (motility, morphology and DNA integrity) identified as effective causes of male infertility (1)and range of fertilization (2). Cells in vivo are exposed to various mechanical stress caused by their environment (3). Everything that comes together with semen handling including: changes in temperature, $\mathrm{pH}$, dilution, increased gravity (at centrifugation), osmotic pressure or toxic effects of the components of the extenders might serve as stress for the sperm (4). Sperm are subjected to physical stresses during ejaculation and contractions of the female tract (5). One of these stresses is hydrostatic pressure, its pressure is exerted by a fluid at equilibrium due to the force of gravity, and exists in all biological environments $(6,7)$. Hydrostatic pressure as a physical-mechanical stress is a crucial component of cell environment and fundamental physical quantity. Also it is the main factor of both integrity and function of cells (8). Sperms exposed to different range of hydrostatic pressure within male reproductive system and during their journey through the female reproductive tract $(9,10)$. These ranges were measured

${ }^{1}$ Department of Biology, Faculty of Basic Sciences, Razi University, Kermanshah, Iran, and ${ }^{2}$ Department of Anatomy, University of Medical Sciences, Hamedan, Iran

Address for correspondence: M. Azadbakht, Department of Biology, Faculty of Basic Sciences, Razi University, Postal Code: 6714967346, Kermanshah, Iran. within male and female reproductive tracts (11). The intraluminal hydrostatic pressure in the testis, seminiferous tubules and in different regions of the epididymis was measured, in the rats, hamsters and guinea-pigs $(9,12)$. In addition it was also measured in the lumen, oviduct, uterus and cervix of female reproductive tract (13). At the pathological states, such as hydrosalpinx in female, vasectomy in the male reproductive tracts, hydrostatic pressure may change and can have adverse effect on sperm motility characteristics, viability and DNA integrity (14-17). Previous studies demonstrated that hydrostatic pressure can change the pattern of sperm motility and block the movement by effects on cytoskeleton and disrupt microtubules and microfilaments in several cellular systems (18-20). These findings showed that mechanical forces play a central role in morphogenesis and tissue patterning (21-23). Hydrostatic Pressure appears as an important tool for investigation of biological systems, (24) in addition sperm is an important participant of fertilization and healthy sperm is necessary for ranges of fertilization successfully $(25,26)$. This study provided evidence that sperm parameters are sensitive to hydrostatic pressure in a time and amount dependent manner.

\section{Materials and methods}

\section{Animals}

Adult 8-12weeks old male and 6-8 weeks old female NMRI mice with a mean weight of $30 \pm 5$ gr (Pastaure institute; Iran) were used. Animals were housed in accordance with the policies of the 
Razi University Animal Care and Use Committee, and the Guide for the Careand Use of Laboratory Animals. The animals were housed in a room kept in mesh cages at $22-24{ }^{\circ} \mathrm{C}$ with a cycle of 12 hours darkness and 12 hours light and fed with standard mouse pellets and water ad libitum.

\section{Preparation of sperm}

Male NMRI mice were sacrificed by cervical dislocation. The cauda epididymides were excised and then placed in 35-mm petri dishes containing HEPES buffered Ham's F-10 culture medium (Ham's F-10-HEPES; Gibco)) supplemented with $10 \%$ fetal bovine serum (FBS; Gibco). Each cauda epididymis was then cut at several places using a fine scissors to allow sperm to swim into the solution for $10-15 \mathrm{~min}$ in an incubator at $37^{\circ} \mathrm{C}$, under an atmosphere of $5 \% \mathrm{CO}_{2}$. The sperm suspension was then gently drawn into a plastic transfer pipette with $2 \mathrm{~mm}$ inner diameter and placed in $5 \mathrm{ml}$ tubes for further experiments (27).

\section{Hydrostatic pressure treatment}

Sperm suspensions were transferred to pressure chamber in 4 well culture plates and were subjected to 25,50 and $100 \mathrm{mmHg}$ hydrostatic pressure (treatments I, II and III; respectively) for 2 and $4 \mathrm{~h}$. In control group, sperms were transferred to another pressure chamber without exposition to hydrostatic pressure. The pressure chamber used in this study is an established model that allows a gas mix pressurized to a constant ambient hydrostatic pressure ranging from $0-200 \pm 2.25 \mathrm{mmHg}$ over the pressure period (28). After pressurization, pressure was restored to atmospheric, and the culture plates removed from the pressure chamber for analysis.

\section{Sperm viability}

The viability of sperms was assessed by trypan blue dye exclusion. Trypan blue dye is impermeable to living cells. One hundred $\mu \mathrm{l}$ sperm suspension $\left(25 \times 10^{6} \mathrm{sperm} / \mathrm{ml}\right)$ was loaded in $1.5 \mathrm{ml}$ eppendorf centrifuge tubes and then $900 \mu \mathrm{l}$ Ham's F-10 - HEPES was added and gently mixed. $10 \mu \mathrm{l}$ of $0.4 \%$ trypan blue dye (v/v; Gibco) to $40 \mu \mathrm{l}$ of sperm suspension was placed in an eppendorf tube and incubated at room temperature for $2 \mathrm{~min}$. Then the sperm suspension was exposed to pressure. Using a light microscope at $40 \mathrm{x}$ magnifications and a hemocytometer counting chamber, the total number of stained and unstained sperm was counted. The relative viability of sperm was determined by dividing the number of unstained sperm by the total number of sperm counted (29).

\section{Sperm motility}

To analyze the motility rate, the sperm suspension $\left(25 \times 10^{6}\right.$ sperm $/ \mathrm{ml}$ ) was placed on a glass slide pre-warmed at $37^{\circ} \mathrm{C}$ and covered with an $18 \times 24 \mathrm{~mm}$ cover slip and visual inspection with 40x objective microscopy over200 was performed and sperms were counted for each sample. Sperm motility was subjectively estimated according to the standard method, photographs were taken in 30 frames per second and sperm motility was recorded on a DVD via a charge-coupled device camera (Progressive 3CCD; Sony, Tokyo, Japan) attached to microscope (IX 70; Olympus,
Tokyo, Japan). Sperm suspension was withdrawn to analyse the movement patterns in treatment and control groups. The sperm motility patterns in this study were as follows: progressive (Fast and Slow), shake and immotile (30).

\section{Sperm morphology}

We used Diff-Quick -staining for detailed sperm morphology assessment. Sperm suspension diluted with distill water and centrifuged $1000 \mathrm{rPm}$ for $3 \mathrm{~min}$ then the sperm sediment used for preparation of smear similar to hematology slide. After air drying of slides we used Diff-Quick for staining the slides. The proportion of morphologically abnormal sperms amorph, giant head, pin head, round head, bent tail, coiled tail and short tail) was assessed according to strict criteria (31). For each sperm sample, 200 sperms were scored from at least 10 individual fields using oil immersion with magnification of $100 \mathrm{x}$ under bright-field oil illumination.

\section{Sperm DNA integrity}

The acridine orange staining $(\mathrm{AO})$ assay was performed briefly, $20 \mu \mathrm{L}$ of washed sperm suspension was smeared on a pre-cleaned glass slide. The smeared slides were air dried and later fixed in Carnoy's solution (1 part glacial acetic acid: 3 parts methanol) for 2 hours. After fixation, slides were air dried and stained with freshly prepared $0.19 \mathrm{mg} / \mathrm{mL}$ AO stain (Polysciences, Warrington, Pa)for 5 minutes in the dark as follows: $10 \mathrm{~mL}$ of $1 \% \mathrm{AO}$ in distilled water added to a mixture of $40 \mathrm{~mL}$ of $0.1 \mathrm{M}$ citric acid and $2.5 \mathrm{~mL}$ of $0.2 \mathrm{M} \mathrm{Na}_{2} \mathrm{HPO}_{4} 0.7 \mathrm{H}_{2} \mathrm{O}$ and $\mathrm{pH}$ adjusted to 2.5. After staining, slides were washed with distilled water, covered with glass cover slips, and immediately evaluated using a fluorescence microscope (AX70 Olympus, Japan) at the excitation wavelength of 450-490 $\mathrm{nm}$. A total of 500 sperm cells were evaluated on each slide by the same examiner with no more than 40 seconds duration of observation per field. Spermatozoa displaying green fluorescence were scored as having normal DNA content, whereas sperm displaying a spectrum of yellow or red fluorescence were considered to have semi-damaged or damaged DNA; respectively (32).

\section{In vitro fertilization}

In vitro fertilization was performed using sperms with hydrostatic pressure exposure (100 $\mathrm{mmHg}$ for $4 \mathrm{~h}$ ) and without hydrostatic pressure exposure as experiment and control groups; respectively. Sperms were washed twice in $\alpha$-MEM supplemented with $16 \mathrm{mg} / \mathrm{mL}$ BSA by centrifugation at $500 \mathrm{x}$ g for $6 \mathrm{~min}$ at room temperature. Sperms at a concentration of $1 \times 10^{6} \mathrm{sperm} / \mathrm{ml}$ concentration were added directly to the $100 \mu \mathrm{l}$ insemination droplets containing the oocytes under mineral oil. The sperm-oocyte mixture was cultured for up to $5 \mathrm{~h}$, by which time nearly all eggs in the treatment and control groups had 2 pronuclei (PN) and the second polar body which were all visible by light microscopy. The eggs with two pronuclei and the second polar body were considered to be fertilized. After $5 \mathrm{~h}$ of co-incubation, all oocytes were then washed and cultured in culture medium (T6 containing $4 \mathrm{mg}$ / $\mathrm{ml} \mathrm{BSA}$ ) at $37^{\circ} \mathrm{C}$ in a humidified atmosphere of $5 \% \mathrm{CO}_{2}$. At 24 $\mathrm{h}$ post-insemination, embryos were observed for determination of cleavage rate (27). 


\section{Statistical analysis}

This experiment consisted of eight replicates. Assessment of sperm quality based on viability, motility, morphology, DNA integrity and the fertilization ability were compared within respective parameters using ANOVA followed LSD test. Means with a probability value of $\mathrm{p}<0.05$ were considered significantly different in this study.

\section{Results}

\section{Viability of sperm}

The percentages of sperm viability in control as well as treatments are shown in Table 1. At the start of experiment the sperm viability was similar to control for all treatments. After $2 \mathrm{~h}$ of exposure to hydrostatic pressure sperm viability decreased in the treatments II and III compared to control $(\mathrm{p}<0.05)$. The differences between treatment I and control were not significant. After $4 \mathrm{~h}$ of exposure to hydrostatic pressure sperm viability decreased in the three treatments compared to control $(\mathrm{p}<0.05)$ (Table 1).

\section{Progressive motility of sperm}

Table 2 provides percentage of progressive motility of mouse epididymal sperm after using the hydrostatic pressure and time. Overall, there was a significant sperm motility difference between treatments and control in their response to hydrostatic pressure $(p<0.05)$. After $2 h$, the percentage of progressive motility in the treatment I was significantly higher than treatments II and III as well as control $(p<0.05)$. The percentage of shaking motility in the treatment II and III was lower than treatment I and control $(p<0.05)$. In addition the mean percentage of immotile sperm in the treatments I, II and III was higher than control $(p<0.05)$. After $4 \mathrm{~h}$, the percentage of progressive sperm in the treatments II and III was lower than treatment I and control $(\mathrm{p}<0.05)$. The percentage of shaking motility in the treatments I, II and III was lower than

Tab. 1. Percentual viability of epididymal mouse sperm that were subjected to hydrostatic pressure.

\begin{tabular}{|c|c|c|c|}
\hline \multirow{2}{*}{ Groups } & $0 \mathrm{~h}$ & $2 \mathrm{~h}$ & $4 \mathrm{~h}$ \\
\hline & Viable $(\%)$ & Viable $(\%)$ & Viable $(\%)$ \\
\hline Control & $80.51 \pm 0.20^{\mathrm{a}}$ & $60.20 \pm 0.50^{\mathrm{a}}$ & $48.90 \pm 0.57^{a}$ \\
\hline Treatment I & $82.20 \pm 0.20^{\mathrm{a}}$ & $58.50 \pm 0.51^{\mathrm{a}}$ & $43.20 \pm 0.50^{\mathrm{b}}$ \\
\hline Treatment II & $81.70 \pm 0.20^{\mathrm{a}}$ & $56.00 \pm 0.53^{b}$ & $40.50 \pm 0.51^{b}$ \\
\hline Treatment III & $80.90 \pm 0.20^{\mathrm{a}}$ & $53.00 \pm 0.56^{\mathrm{b}}$ & $38.41 \pm 0.53^{\mathrm{b}}$ \\
\hline
\end{tabular}

Tab. 3. Percentage of abnormal morphology of epididymal mouse sperm that were subjected to hydrostatic pressure.

\begin{tabular}{lccccc}
\hline \multirow{2}{*}{ Groups } & \multicolumn{2}{c}{$2 \mathrm{~h}$} & & \multicolumn{2}{c}{$4 \mathrm{~h}$} \\
\cline { 2 - 3 } \cline { 5 - 6 } & $\begin{array}{c}\text { Normal } \\
(\%)\end{array}$ & $\begin{array}{c}\text { Abnormal } \\
(\%)\end{array}$ & & $\begin{array}{c}\text { Normal } \\
(\%)\end{array}$ & $\begin{array}{c}\text { Abnormal } \\
(\%)\end{array}$ \\
\hline Control & $65.00 \pm 0.50^{\mathrm{a}}$ & $35.00 \pm 0.80^{\mathrm{a}}$ & & $58.00 \pm 0.70^{\mathrm{a}}$ & $42.00 \pm 0.85^{\mathrm{a}}$ \\
Treatment I & $63.25 \pm 0.57^{\mathrm{a}}$ & $36.75 \pm 0.86^{\mathrm{a}}$ & & $55.50 \pm 0.78^{\mathrm{b}}$ & $44.50 \pm 0.80^{\mathrm{b}}$ \\
Treatment II & $61.22 \pm 0.57^{\mathrm{b}}$ & $38.78 \pm 0.72^{\mathrm{b}}$ & & $50.22 \pm 0.75^{\mathrm{b}}$ & $50.50 \pm 0.87^{\mathrm{b}}$ \\
Treatment III & $60.22 \pm 0.54^{\mathrm{b}}$ & $39.78 \pm 0.74^{\mathrm{b}}$ & & $45.48 \pm 0.75^{\mathrm{b}}$ & $54.52 \pm 0.81^{\mathrm{b}}$ \\
\hline Control: without hydrostatic pressure exposure; Treatment I, II and III: with exposure \\
to hydrostatic pressure (25, 50 and 100 mmHg; respectively) \\
abb: Values within columns with different superscripts are significantly different. \\
Data are means \pm SEM (ANOVA, p<0.05).
\end{tabular}

control $(p<0.05)$. The percentage of immotile sperm in the treatments I, II and III was higher than in control $(\mathrm{p}<0.05)$.

\section{Morphology of sperm}

The difference in the percentage of abnormal morphology of epididymal mouse sperm that was subjected to hydrostatic pressure is given in Table 3. Results showed that sperm morphology was changed after exposure to hydrostatic pressure in the treatments. Quantitative analyses of sperm morphology revealed that after 2 $\mathrm{h}$, the percentage of sperm normal morphology decreased in the treatments II and III compared to control $(\mathrm{p}<0.05)$. There was no significant difference between treatment I and control. After $4 \mathrm{~h}$, the percentage of sperm normal morphology in the three treatments decreased compared to control $(\mathrm{p}<0.05)$ (Tab.3).

\section{DNA integrity of sperm}

Based on the acridine orange staining, after 2 and $4 \mathrm{~h}$ the percentage of normal DNA content sperm (green fluorescence) in control was higher than all treatments $(p<0.05)$. The percentage of normal DNA content sperm was decreasing from treatment I to treatment III $(\mathrm{p}<0.05)$. The percentage of semi-damaged DNA content sperm (yellow fluorescence) in treatment III was higher than treatments I, II and control $(\mathrm{p}<0.05)$. The percentages of semi-damaged DNA content sperm (yellow fluorescence) as well as damaged DNA content sperm (red fluorescence) in treatment III were higher than treatments I, II and control $(\mathrm{p}<0.05)$ (Tab. 4).

\section{Sperm fertilizing ability}

After $4 \mathrm{~h}$, the percentage of pronuclei (PN) which were visible by light microscopy, in the control was more than in comparison to treatment. However there was no significant difference between control and treatment. $24 \mathrm{~h}$ after in vitro fertilization, control and treatment groups were evaluated for the percentage

Tab. 2. Percentages of progressive motility of epididymal mouse sperm that were subjected to hydrostatic pressure.

\begin{tabular}{|c|c|c|c|c|c|c|}
\hline \multirow{2}{*}{ Groups } & \multicolumn{3}{|c|}{$2 \mathrm{~h}$} & \multicolumn{3}{|c|}{$4 \mathrm{~h}$} \\
\hline & Progressive (\%) & Shake (\%) & Immotile (\%) & Progressive (\%) & Shake (\%) & Immotile $(\%)$ \\
\hline Control & $18.12 \pm 0.70^{\mathrm{a}}$ & $42.06 \pm 0.84^{\mathrm{a}}$ & $39.82 \pm 0.50^{\mathrm{a}}$ & $15.80 \pm 0.88^{\mathrm{a}}$ & $37.07 \pm 0.78^{\mathrm{a}}$ & $47.13 \pm 0.80^{\mathrm{a}}$ \\
\hline Treatment I & $26.10 \pm 0.75^{b}$ & $40.40 \pm 0.86^{\mathrm{a}}$ & $33.50 \pm 0.54^{\mathrm{b}}$ & $14.60 \pm 0.80^{\mathrm{a}}$ & $32.88 \pm 0.75^{b}$ & $52.52 \pm 0.83^{b}$ \\
\hline Treatment II & $14.29 \pm 0.71^{\mathrm{c}}$ & $36.80 \pm 0.80^{\mathrm{b}}$ & $48.91 \pm 0.57^{\mathrm{c}}$ & $12.20 \pm 0.81^{\mathrm{b}}$ & $27.70 \pm 0.86^{\mathrm{c}}$ & $60.10 \pm 0.70^{c}$ \\
\hline Treatment III & $10.84 \pm 0.78^{c}$ & $38.80 \pm 0.82^{\mathrm{b}}$ & $50.36 \pm 0.59^{c}$ & $8.50 \pm 0.85^{\mathrm{b}}$ & $11.46 \pm 0.72^{\mathrm{d}}$ & $80.04 \pm 0.88^{d}$ \\
\hline
\end{tabular}

Control: without hydrostatic pressure exposure; Treatment I, II and III: with exposure to hydrostatic pressure (25, 50 and $100 \mathrm{mmHg}$; respectively)

ab/c/d: Values within columns with different superscripts are significantly different.

Data are means \pm SEM (ANOVA, $\mathrm{p}<0.05)$ 
Tab. 4. DNA integrity of epididymal mouse sperm that were subjected to hydrostatic pressure.

\begin{tabular}{|c|c|c|c|c|c|c|}
\hline \multirow{2}{*}{ Groups } & \multicolumn{3}{|c|}{$2 \mathrm{~h}$} & \multicolumn{3}{|c|}{$4 \mathrm{~h}$} \\
\hline & Green (\%) & Yellow (\%) & Red (\%) & Green (\%) & Yellow (\%) & Red (\%) \\
\hline Control & $100.00 \pm 0.80^{\mathrm{a}}$ & $0.00 \pm 0.84^{\mathrm{a}}$ & $0.00 \pm 0.50^{\mathrm{a}}$ & $100.00 \pm 0.88^{\mathrm{a}}$ & $0.00 \pm 0.78^{\mathrm{a}}$ & $0.00 \pm 0.80^{\mathrm{a}}$ \\
\hline Treatment I & $78.10 \pm 0.85^{\mathrm{b}}$ & $20.20 \pm 0.86^{b}$ & $1.70 \pm 0.54^{b}$ & $65.80 \pm 0.86^{b}$ & $30.40 \pm 0.75^{\mathrm{b}}$ & $3.80 \pm 0.84^{b}$ \\
\hline Treatment II & $55.40 \pm 0.81^{\mathrm{c}}$ & $37.50 \pm 0.80^{\mathrm{c}}$ & 7. $10 \pm 0.57^{\mathrm{c}}$ & $40.20 \pm 0.81^{\mathrm{c}}$ & $48.40 \pm 0.77^{\mathrm{c}}$ & $11.40 \pm 0.86^{\mathrm{c}}$ \\
\hline Treatment III & $20.40 \pm 0.88^{\mathrm{d}}$ & $58.40 \pm 0.83^{\mathrm{d}}$ & $21.20 \pm 0.59^{d}$ & $9.80 \pm 0.85^{\mathrm{d}}$ & $44.80 \pm 0.72^{\mathrm{d}}$ & $35.00 \pm 0.88^{\mathrm{d}}$ \\
\hline
\end{tabular}

Control: without hydrostatic pressure exposure; Treatment I, II and III: with exposure to hydrostatic pressure (25, 50 and $100 \mathrm{mmHg}$; respectively)

a'b: Values within columns with different superscripts are significantly different.

Data are means \pm SEM (ANOVA, $\mathrm{p}<0.05)$.

Tab. 5. In vitro fertilization rate of epididymal mouse sperm that were subjected to hydrostatic pressure.

\begin{tabular}{lccc}
\hline & & $5 \mathrm{~h}$ & $24 \mathrm{~h}$ \\
\hline Groups & $\mathrm{n}$ & $\mathrm{PN}(\%)$ & $2-C e l l s(\%)$ \\
Control & 84 & $67.88 \pm 0.80^{\mathrm{a}}$ & $55.14 \pm 0.50^{\mathrm{a}}$ \\
Treatment & 78 & $63.98 \pm 0.85^{\mathrm{a}}$ & $10.63 \pm 0.57^{\mathrm{b}}$ \\
\hline
\end{tabular}

Control: without hydrostatic pressure exposure; Treatment: with exposure to hydrostatic pressure $(100 \mathrm{mmHg})$

a'b: Values within columns with different superscripts are significantly different.

Data are means \pm SEM (ANOVA, $\mathrm{p}<0.05$ ).

of 2-cells embryo. The percentage of 2-cells embryo decreased dramatically in the treatment groups in comparison to control group $(\mathrm{p}<0.05)$ (Tab. 5).

\section{Discussion}

Pressure is a dynamical parameter that was recently used in research and industrial applications (33). The development of pressure as a tool in the research field has emerged from the end of the sixth century (34). Today pressure appears as an important tool for the investigation of biological systems (24). Hydrostatic pressure and hydrodynamics are among the most fundamental physical properties that determine cell form and function. Cells in vivo are exposed to various mechanical forces caused by their environment (3), and rapidly respond to changes in volume and osmotic potential differences across the plasma membrane $(7,35)$. Mechanical stimulation alters morphology and differentiation of connective tissue cells. Specifically, hydrostatic pressure alters cellular cytoskeleton and metabolic activity (25). So far different ranges of hydrostatic pressure studied in many biological systems, the effects of micro-pressures manifest in the physiology of certain cells and the behavior of many animals (6) and sublethal environmental stress, high-hydrostatic pressure was reported to significantly improve the motility, viability and fertility parameters of frozen semen (36). Effect of hydrostatic pressure was studied on the ascaris cytoskeleton and sperm motility (18). The results of current study demonstrate that after applying hydrostatic pressure in the three treatment groups 25,50 and $100 \mathrm{mmHg}$ for 2 and $4 \mathrm{~h}$, sperm parameters such as, viability, motility, morphology and DNA integrity were affected. Increase of hydrostatic pressure depending on the amount and duration caused reduction of sperm quality due to increasing abnormality in morphology (amorph, giant head, pin head, round head, bent tail, coiled tail and short tail), reducing viability and motility, inducing DNA damage of sperm as well as reducing sperm fertilizing ability.
Normal sperm morphology correlated with function necessary for motility (1), experimental studies confirm that high percentage of abnormal sperm is associated with an impaired fertilization rate of in vitro fertilization $(37,38)$. Sperm chromatin integrity is vital for successful pregnancy and transmission of genetic material to the offspring (39). Condensation of sperm nuclear chromatin correlated with morphology of sperm and this can affect sperm motility. Thus hydrostatic pressure with changes in condensation of chromatin causes changes in the morphology and motility of sperm (40).

In this study to apply pressure directly, we used pressure system with designed specialized between the pressure chambers base upon an established model incorporating a perspex and glass chamber with gas inlet and flow valves for connection to a lowpressure regulator. The desired gas mix can be pressurized to a constant ambient hydrostatic pressure ranging from 0 to $200 \mathrm{mmHg}$ (28). We applied pressure chamber to visualize directly the influence of pressure on the viability, motility, morphology, DNA integrity and sperm fertilizing ability with functional-morphological view. We observed that increase amount of hydrostatic pressure reduced sperm viability in treatment groups significantly at 100 $\mathrm{mmHg}$ after $4 \mathrm{hr}$. One cause of decreased viability may be intesification of pressure effects depended on duration and failure of self- revitalization of some sperms after exposure to pressure, that may be a consequence of changes in plasma membrane. Evaluation of movement characteristics was presented in this paper and demonstrated that increased hydrostatic pressure affected sperms movement, after applying $25 \mathrm{mmHg}$ for $2 \mathrm{~h}$, we observed relative increase in the percentage of progressive motility that may be due to sperm activation. Activation of sperm is a prerequisite for hyperactivation, it may be critical for the success of fertilization, various factors including: increase of calcium concentration, glucose, bicarbonate and etc causing activation (41-43). While hydrostatic pressure can activate mechanosensitive ion channels $(35,44)$, may this amount of pressure affect on sperm ion channels and cause to activation. In this treatment after $4 \mathrm{~h}$, the percentage of progressive and shaking motility was reduced and the mean percentage of immotile sperm increased, it may be this amount of pressure was the primary stress for the sperm. After applying hydrostatic pressure 50 and $100 \mathrm{mmHg}$ for 2 and $4 \mathrm{~h}$, the percentage of progressive and shaking motility was decreased and the percentage of immotile sperm increased. This was significant for hydrostatic pressure of $100 \mathrm{mmHg}$ for $4 \mathrm{~h}$. This result can represent, hydrostatic pressure, $50 \mathrm{mmHg}$ for $4 \mathrm{~h}$, may be the treshold pathological amount of pressure and $100 \mathrm{mmHg}$ hydrostatic pressure has disruptive effects on the sperm movement, moreover function and 
vital behaviors. Sperm motility gives a measure of the integrity of the sperm axoneme and tail structures as well as the metabolic machinery of the mitochondria (45). Therefore decrease of sperm movement, especially progressive motility after applying hydrostatic pressure, may be due to sperm membrane damage in the tail, head and mid piece. Analysis of sperm morphology indicated that after applying hydrostatic pressure of 50 and $100 \mathrm{mmHg}$ for $2 \mathrm{~h}$, the percentage of sperm with normal morphology reduced and the percentage of abnormal sperm increased but there was no significant difference between control and treatment at $25 \mathrm{mmHg}$. After $4 \mathrm{~h}$, in the three treatment grups 25, 50 and $100 \mathrm{mmHg}$ the percentage of sperm with normal morphology reduced and the percentage of abnormal sperm increased, stronger changes of morphology occurred especially in the sperm's tail at $100 \mathrm{mmHg}$ for $4 \mathrm{~h}$. In this study, the sperm with damaged chromatin (yellow, red fluorescence) increased after applying hydrostatic pressure in the three treatment groups for 2 and $4 \mathrm{~h}$, these increases were significant in the treatment with $100 \mathrm{mmHg}$ for $4 \mathrm{~h}$. The chance of a successful pregnancy is low with severe anomalies of the sperm head shape. Moreover, sperm decondensation defects and DNA anomalies might be the main factors affecting the fertilization capacity of sperm (45). Our study demonstrated after applying hydrostatic pressure of $100 \mathrm{mmHg}$ for $4 \mathrm{~h}$, as a disruptive range that the percentage of 2-cells embryo decreased dramatically in the treatment group. These failures may be due to sperm with damaged chromatin, anomalies of the sperm morphology and motility pattern defects that were induced by hydrostatic pressure. It can be concluded that hydrostatic pressure reduces sperm quality as a consequence of adverse effects on sperm parameters and may cause male infertility or subfertility.

\section{References}

1. Gandini L, Lombardo F, Paoli D, Copenecchia L, Familiari G, Verlengia C. Study of apoptatic DNA fragmentation in human spermatozoa. Hum Reprod 2000; 15 (4): 830-839.

2. Rajender H, Singh L, Thangaraj K. Phenotypic heterogeneity of mutations in androgen receptor gene. J Asian Androl 2007; 9 (2): 147-179.

3. Sironen R, Elo M, Kaarniranta K, Helminen H, Lammi M. Transcriptional activation in chondrocytes submitted to hydrostatic pressure. Biorheology 2000; 37 (1-2): 85-93.

4. Pribenszky C, Horvath A, Vegh L, Huang Y, Kuo H, Szenci O. StressPreconditioningofBoar Spermatozoa: ANew Approach to Enhance Semen Quality. Reprod in Domestic Animals 2011; 46 (2): 26-30.

5. Menge A, Edwards R. Mucosal immunity of the reproductive tract and infertility. Immuno Reprod 1993; 40 (3): 9-36.

6. Macdonald G. Hydrostatic Pressure as an Environmental Factor in Life Processes. Comp Biochem Physiol 1997; 116 (4): 291-297.

7. Zonia L, Munnik T. Hydrodynamics and cell volume oscillations in the pollen tube apical region are integral components of the biomechanics of Nicotiana tabacum pollen tube growth. Cell Biochem Biophys 2006; 46 (3): 209-232.

8. Tan J, Kalapesi F, Coroneo M. Mechanosensitivity and The eye: Cells coping with the pressure. J Br Ophthalmol 2006; 90 (3): 383-388.
9. Johnson A, Howards S. Intratubular hydrostatic pressure in testis and epididymis before and after long-term vasectomy in the guinea-pig. Bio Reprod 1976; 14 (4): 371-376.

10. Suarez S, Katz D, Overstreet J. Properties of luminal fluids and epithelial surfaces may affect fertilization by influencing sperm movement. Bio Reprod 1983; 29 (2): 277-1287.

11. Hib J, Ponzio R, Vilar O. Contractility of the rat caudaepididymidis and vas deferens during seminal emission. J Reprod Fertil 1982; 66 (1): 47-50.

12. Johnson A, Howards $\mathbf{S}$. Intratubular hydrostatic pressure in testis and epididymis before and after vasectomy. J Physiol 1975; 228 (2): 556-564.

13. Suzuki H, Yoshio T. Intraluminal pressure changes in the Oviduct, uterus and cervix of the mated rabbit. Bio Reprod 1981; 24 (1): 723-733.

14. Hug E, AjonumaL, Yee E, Yeung S, Ho P. Adverse effect of hydrosalpinx fluid on spermatozoa motility and survival. Hum Reprod 2000; 15 (4): 772-777.

15. Paducah D, Skoog S. Current Management of Adolescent Varicocele. Rev Urol 2001; 3 (3): 120-133.

16. Ajonuma L, Nq E, Chan H. New insights into the mechanisms underlying hydrosalpinx fluid formation and its advers effect on IVF outcome. Hum Reprod 2002; 8 (3): 255-264.

17. Steger K, Slovov M, Failing K, Weidner W, Bergmann M. Effect of vasectomy on sperm nuclear chromatin condensation in the rabbit. J Androl 2005; 26 (2): 289-295.

18. Thomas M, Salmon E, and StewarM. Hydrostatic Pressure Shows That Lamellipodial Motility in AscarisSperm Requires Membrane-associated Major Sperm Protein Filament Nucleation and Elongation. J Cell Bio1998; 140 (2): 367-375.

19. Haskin C, Cameron I, Athanasiou K. Physiological levels of hydrostatic pressure alters morphology and organization of cytoskeletal and adhesion proteins in MG-63 osteosarcoma cells. Biochem Cell Biol 1993; 71 (1-2): 27-35.

20. Crenshaw H, Allen J, Skeen V, Harris A, Salmon E. Hydrostatic pressure has different effects on the assembly of tubulin, actin, myosin II, talin, vimentin, and cytokeratin in mammalian tissue cells. Exp Cell Res 1996; 227 (2): 285-297.

21. Parker K, Brock A, Brangwynne C, Mannix R, Wang N, OstuniE, Geisse N, et al. Directional control of lamellipodia extension by constraining cell shape andorienting cell tractional forces. J Faseb 2002; 16 (10): 1195-1204.

22. Nelson C, Jean R, Tan J, Liu W, Sniadecki N, Spector A, Chen C. Emergent patterns of growth controlled by multicellular Form and mechanics. Proc Natl Acad Sci 2005; 109 (28): 11594-11599.

23. Mammoto A, Connor K, Mammoto T, Yung ,Huh D, Aderman C, Mostoslavsky G, Smith LE, Ingber DE. A mechanosensitive transcriptional mechanism that controls angiogenesis. Nature2009; 457 (7233): 1103-1108.

24. Winter R, Dzwolak W. Exploring the temperature-pressure configurational landscape of biomolecules: from lipid membranes to proteins. Philos Trans Res 2005; 363 (1827): 537-563.

25. Liu J, Zou L, Wang J, Schuler C, Zhao Z, Li X, Zhang J, Liu Y. Hydrostaticpressure promotes Wnt10b and Wnt4 expression dependent and independenton ERK signaling in early-osteoinduced MSCs. Biochem Biophys 2009; 379 (2): 505-509. 
26. Chemes E, Rawe Y. Sperm pathology: a step beyond descriptive morphology. Origin characterization and fertility potential of abnormal sperm phenotypes in infertile men. Hum Reprod 2003; 9 (5): 405-428.

27. Emma and Fesa. In vitro fertilization of mouse oocyte using HTF medium. An In center for mouse Genetic 2008.

28. Agar A, Yip S, Hill M, Coroneo M. Pressure related apoptosis in neuronal cell lines. J Neurosci Res 2000; 60 (4): 495-593.

29. Rashidi I, Movahedi M, Tiraihi T. The effect of pentoxifyline on mouse epididymal sperm parameters. IR J Reprod Med 2004; 2 (2): 51-57.

30. Hayati A, Rahmaninta A, Pidada R. Spermatozoa motility and morphological recovery process in mice after the induction of 2-methoxyethanol. Biol Reprod 2005; 90; 121-125.

31. Kruger T, Acosta A, Simmons K, Swanson R, Matta J, Oehninger S. Predictive value of abnormal sperm morphology in in vitro fertilization. Fertil Steril 1988; 49 (1): 112 -117.

32. Martins C, Dode M, Baoand S, Rumpf R. The use of the acridine orange test and the TUNEL assay to assess the integrity of freeze-dried bovine spermatozoa DNA. Genet Mol Res 2007; 6 (1): 94-104.

33. Demazeau G, Rivalain N. The development of high hydrostatic pressure processes asan alternative to other pathogen reduction methods. J Applied Microbiol 2010; 110 (6): 1364-5072.

34. Hite B. The effect of pressure in the preservation of milk. BullVirginia Univ Agric Exp 1899; 58 (1): 15-35.

35. Shope J, Dewald D, Mott K. Changes in surface area of intact guard cells are correlated with membrane internalization. Plant Physiol 2003; 159 (3): 1314-1321.
36. Huang S, Pribenszky C, Kuo Y, Teng S, Chen Y, Chung M, Chiu Y. Hydrostatic pressure pre-treatment affects the protein profile of boar sperm before and after freezing-thawing. Anim Reprod Sci 2009; 112 (1-2): 136-49.

37. Aziz N, Buchan I, Taylor C, Kingsland C, Lewis I. The sperm deformity index: a reliable predictor of the outcome of oocyte fertilisation in vitro. Fertil Steril 1996; 66 (6): $1000-1008$.

38. Kawai Y, Hata T, Suzuk O, Matsuda J. The relationship between sperm morphology and in vitro fertilization ability in mice. J Reprod Develop 2006; 52 (4): 561-568.

39. Chohan K, Griffin J, Lafromboise M, Jonge C. Comparison of Chromatin Assays for DNA Fragmentation Evaluation in Human Sperm. J Androl 2006; 27 (1): 53-59.

40. Grootegoed J, Siep M, Baarends M. Molecular and cellular mechanisms in spermatogenesis. Res Endo Metabol 2000; 14 (3): 331-343.

41. Yanagimachi R. The movement of golden hamster spermatozoa before and after capacitation. Reprod Fertil 1970; 23 (1): 193-196.

42. Suarez S. Hyperactivation of mammalian spermatozoa - Function and regulation. Reprod 2001; 122 (4): 519-526.

43. Carlson A, Hille B, Babcock D. External $\mathrm{Ca}^{+2}$ acts upstream of adenylyl cyclase $\mathrm{SACY}$ in the bicarbonate signaled activation of sperm motility. Dev Biol 2007; 312 (1): 183-192.

44. Tokuda S, Niisato N, Nagai T, Taruno A, Nakajima K, Miyazaki H, Yamada T et al. Regulation of paracellular Nal and $\mathrm{Cl}$ conductances by hydrostatic pressure. Cell Bio 2009; 33 (9): 949-956.

45. Karpuz V, Gokturk A, Koyuturk M. The effects of sperm morphology and motility on the outcome of intracytoplasmic sperm injection. $\mathrm{J}$ Marmara Medi 2007; 20 (2): 92-97. 